\title{
PENINGKATAN KUALITAS PEMBELAJARAN TEKNOLOGI KOMPUTER TERHADAP KONDISI SARANA PRASARANA DAN PROSES PEMBELAJARAN SEKOLAH MENENGAH KEJURUAN ISLAM KADER BANGSA BEKASI-UTARA.
}

\author{
Halimah Tunafiah \\ Jurusan Teknik Sipil, FT-Universitas Persada Indonesia Y.A.I, \\ Jl. Salemba Raya 7/9A Jakarta Pusat, \\ Telp. 021-3914075/76, Fax.021-3147910 \\ e-mail: htunafiah@gmail.com
}

\begin{abstract}
ABSTRAK
Kinerja dosen di Perguruan Tinggi adalah menjalankan Tri Dharma Perguruan Tinggi, salah satunya adalah menjalankan kegiatan pengabdian masyarakat berupa kegiatan pembelajaran pada Sekolah Menengah Kejuruan Kader Bangsa terletak di Jl. Ceremai II Komplek SBS Kec. Bekasi Utara, Kab. Bekasi, Prop. Jawa Barat.

Pada kegiatan inilah sekaligus dilakukan kajian dan evaluasi melalui penelitian kualitatif terhadap Kondisi Sarana Prasarana dan Proses Pembelajaran Sekolah.

Teknologi Komputer, digunakan siswa mampu menggali dan memproses ilmu pengetahuan dalam kegiatan belajar, bekerja dan aktivitas lainnya. Atas dasar inilah dibutuhan peningkatan kualitas pembelajaran yang terkait dengan kualitas Sarana dan Prasarana serta Proses Pembelajaran. Data dari hasil penyebaran kuisioner kepada kepala sekolah dan para guru yang terdiri dari aspek penilaian yang sama pada sarana dan prasarana sekolah serta proses pembelajaran kemudian di analisis pengaruhnya terhadap peningkatan kualitas pembelajaran dengan menggunakan program SPSS 20. Dari analisis program SPSS 20 dihasilkan kondisi sarana dan prasarana yang ada sangat perlu untuk ditingkatkan untuk meningkatkan kualitas pembelajaran
\end{abstract}

Kata Kunci: Teknologi, Komputer, Sarana dan Prasarana, Pembelajaran.

\section{PENDAHULUAN}

Kinerja dosen di Perguruan Tinggi adalah menjalankan Tri Dharma Perguruan Tinggi, salah satunya adalah menjalankan kegiatan pengabdian masyarakat berupa kegiatan pembelajaran pada Sekolah menengah kejuruan kader bangsa terletak di kampung teluk angsan lengkek/keramat tepatnya terletak di Jl. Ceremai II Komplek SBS Kec. Bekasi Utara, Kab. Bekasi, Prop. Jawa Barat.

Sekolah menengah kejurusan merupakan salah satu bentuk satuan pendidikan formal yang menyelenggarakan pendidikan kejuruan jenjang pendidikan menengah sebagai lanjutan dari Sekolah menengah pertama, atau bentuk lain yang sederajat atau lanjutan dari hasil belajar yang diakui sama/setara SMP/MTs.

Sekolah menengah kejuruan kader bangsa memiliki beberapa jurusan diantaranya jurusan akuntasi, manajemen dan perdagangan. Jurusan akuntansi ini terdapat pembelajaran akuntansi berbasis komputer yang dikenal dengan nama $M Y O B$
(Mind Your Own Bussines) yang diajarkan pada kelas XI dan XII.

Melalui Pembelajaran Teknologi Keuangan berbasis $M Y O B$ inilah tim pengabdian melaksanakan kajian dan evaluasi terhadap kondisi Sarana Prasarana dan Proses Pembelajaran Sekolah Menengah Kejuruan Islam Kader Bangsa Bekasi Utara.

\section{BATASAN PENULISAN PENELITIAN}

Pada penulisan ini dibatasi pada penelitian hasil pengabdian pada masyarakat pada SMK Islam Kader Bangsa tersebut berlokasi di jalan ceremai 11 komplek SBS, Kelurahan Harapan Jaya, Kecamatan Bekasi Utara, Kabupaten Bekasi, Propinsi Jawa Barat. Meliputi: Aspek penilaian terhadap sarana dan prasarana sekolah. Aspek penilaian tersebut menggunakan skala sebagai berikut:
$4=\mathrm{A}$ (Memuaskan)
$3=\mathrm{B}$ (Baik)
$2=\mathrm{C}$ (Cukup)
$1=\mathrm{D}$ (Kurang) 


\subsection{Sarana dan Prasarana Sekolah}

Kemampuan akademik perlu ditunjang dengan lengkapnya Sarana dan Prasarana. Adapun aspek penilaian terhadap sarana dan prasarana tersebut seperti tabel 1 . Sebagai berikut:

Tabel 1

Sarana dan Prasarana Sekolah

\begin{tabular}{|c|c|c|c|c|c|}
\hline No. & Aspek yang dinilai & 4 & 3 & 2 & 1 \\
\hline 1. & Lahan Sekolah & & & & \\
\hline 2. & Bangunan Sekolah & & & & \\
\hline 3. & Gudang & & & & \\
\hline 4. & Ruang Sirkulasi & & & & \\
\hline 5. & Ruang kepala sekolah & & & & \\
\hline 6. & Ruang wakil kepala sekolah & & & & \\
\hline 7. & Ruang administrasi & & & & \\
\hline 8. & Ruang guru & & & & \\
\hline 9. & Ruang konseling & & & & \\
\hline 10. & Ruang pertemuan siswa & & & & \\
\hline 11. & Ruang serbaguna & & & & \\
\hline 12. & Ruang UKS & & & & \\
\hline 13. & Tempat berolahraga & & & & \\
\hline 14. & Tempat bermain & & & & \\
\hline 15. & Kantin & & & & \\
\hline 16. & Klinik & & & & \\
\hline 17. & Laboratorium komputer & & & & \\
\hline 18. & Perpustakaan & & & & \\
\hline 19. & Ruang belajar & & & & \\
\hline 20. & Fasilitas kesenian & & & & \\
\hline 21. & Ruang ibadah & & & & \\
\hline 22. & Toilet & & & & \\
\hline
\end{tabular}

\subsection{Proses Pembelajaran}

Proses pembelajaran perlu mengimbangi perkembangan Informasi dan teknologi yang sangat pesat, dibutuhkan strategi yang tepat untuk menimbulkan rasa ingin tahu dan motivasi siswa, terjalinnya hubungan dan komunikasi yang baik dari pihak terkait, dan tingkah laku siswa dalam beraktivitas di dalam pembelajaran. Adapun aspek penilaian terhadap proses pembelajaran tersebut seperti tabel 2 . Sebagai berikut:

Tabel 2

Proses Pembelajaran

\begin{tabular}{|c|c|c|c|c|c|}
\hline No. & Aspek yang dinilai & 4 & 3 & 2 & 1 \\
\hline 1. & $\begin{array}{l}\text { Rasa ingin tahu siswa terhadap } \\
\text { pelajaran }\end{array}$ & & & & \\
\hline 2. & Motivasi siswa terhadap pelajaran & & & & \\
\hline 3. & Hubungan siswa dengan guru & & & & \\
\hline 4. & Hubungan siswa dengan siswa & & & & \\
\hline 5. & $\begin{array}{l}\text { Hubungan guru dengan orang tua } \\
\text { atau wali siswa }\end{array}$ & & & & \\
\hline 6. & $\begin{array}{l}\text { Komunikasi dua arah siswa dengan } \\
\text { guru }\end{array}$ & & & & \\
\hline 7. & $\begin{array}{l}\text { Komunikasi dua arah siswa dengan } \\
\text { siswa }\end{array}$ & & & & \\
\hline 8. & $\begin{array}{l}\text { Komunikasi dua arah guru dengan } \\
\text { orang tua atau wali siswa }\end{array}$ & & & & \\
\hline 9. & $\begin{array}{l}\text { Aktivitas dan proses pembelajaran } \\
\text { siswa }\end{array}$ & & & & \\
\hline 10. & $\begin{array}{l}\text { Pemanfaatan sumber belajar lain } \\
\text { selain guru (lingkungan, nara sumber, } \\
\text { teknologi komputer) }\end{array}$ & & & & \\
\hline
\end{tabular}

Dari Aspek penilaian terhadap sarana dan prasarana serta proses pembelajaran yang telah dilakukan oleh tim pengabdian (tim dosen yang terdiri dari Dosen Teknik Sipil dan Teknik Informatika), di evaluasi kembali melalui penyebaran kuisioner kepada kepala sekolah dan para guru. Data dari hasil penyebaran kuisioner kepada kepala sekolah dan para guru yang terdiri dari aspek penilaian yang sama pada sarana dan prasarana sekolah di analisis pengaruhnya terhadap peningkatan kualitas pembelajaran dengan menggunakan program SPSS 20.

\subsection{Hasil Analisis SPSS 20 Aspek Penilaian Sarana dan Prasarana Sekolah}

\begin{tabular}{|c|c|c|c|c|c|}
\hline \multicolumn{6}{|c|}{$\begin{array}{c}\text { Tabel } 3 . \\
\text { Model Summary }\end{array}$} \\
\hline Model & $\bar{R}$ & R Square & Adjusted R Square & \begin{tabular}{|c|} 
Std. Error of the \\
Estimate
\end{tabular} & Durbin-Watson \\
\hline 1 & ,680 & , 463 & , 021 & ,754 & 2,402 \\
\hline 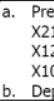 & $\begin{array}{l}\text { uang } \\
\text { dent }\end{array}$ & $\begin{array}{l}\text { pertemuan } \\
\text { Variable: } Y \text { : }\end{array}$ & $\begin{array}{l}\text { siswa, X6: Ruang wa } \\
\text { Kualitas Pembelajarar }\end{array}$ & $\begin{array}{l}\text { berolahrac } \\
\text { 8: Ruang } \\
\text { administra } \\
\text { epala seko }\end{array}$ & $\begin{array}{l}\text { Perpustakaan, } \\
\text { 19: Ruang belajar, } \\
\text { Bangunan Sekolah, } \\
\text { 6: Klinik }\end{array}$ \\
\hline
\end{tabular}

\begin{tabular}{|c|c|c|c|c|c|c|}
\hline \multicolumn{7}{|c|}{$\begin{array}{l}\text { Tabel } 4 . \\
\text { ANOVA }^{\mathrm{a}}\end{array}$} \\
\hline Mode & & $\begin{array}{l}\text { Sum of } \\
\text { Squares }\end{array}$ & df & Mean Square & $\mathrm{F}$ & Sig. \\
\hline \multirow{3}{*}{1} & Regression & 8,333 & 14 &, 595 & 1,047 & $.458^{6}$ \\
\hline & \begin{tabular}{|l|} 
Residual \\
\end{tabular} & 9,667 & 17 &, 569 & & \\
\hline & Total & 18,000 & 31 & & & \\
\hline \multicolumn{7}{|c|}{$\begin{array}{l}\text { a. Dependent Variable: Y:Kualitas Pembelajaran } \\
\text { b. Predictors: (Constant), X22: Toilet, X13: Tempat berolahraga, X18: Perpustakaan, } \\
\text { X21: Ruang ibadah, X5: Ruang kepala sekolah, X8: Ruang guru, X19: Ruang belajar, } \\
\text { X12: Ruang UKS, X1: Lahan Sekolah, X7: Ruang administrasi, X2: Bangunan Sekolah, } \\
\text { X10: Ruang pertemuan siswa, X6: Ruang wakil kepala sekolah, X16: Klinik }\end{array}$} \\
\hline
\end{tabular}

\begin{tabular}{|c|c|c|c|c|c|c|}
\hline & & $\begin{array}{c}\text { Tab } \\
\text { Coeffi }\end{array}$ & $\begin{array}{l}\text { el } 5 . \\
\text { icients }\end{array}$ & & & \\
\hline Mo & & $\begin{array}{l}\text { Unstand } \\
\text { Coeffic }\end{array}$ & $\begin{array}{l}\text { ardized } \\
\text { cients }\end{array}$ & \begin{tabular}{|c|} 
Standardized \\
Coefficients
\end{tabular} & $\mathrm{t}$ & Sig. \\
\hline & & B & Std. Error & Beta & & \\
\hline & (Constant) & 317 & 3,727 & & ,085 & 933 \\
\hline & X1: Lahan Sekolah & 1,109 & ,512 & ,686 & 2,168 & ,045 \\
\hline & X2: Bangunan Sekolah & -616 & 917 &,- 381 & -672 & .511 \\
\hline & $\begin{array}{l}\text { 55: Ruang kepala } \\
\text { sekolah }\end{array}$ & -103 &, 516 & -094 &,- 200 & 844 \\
\hline & $\begin{array}{l}\text { X6: Ruang wakil } \\
\text { kepala sekolah }\end{array}$ & 039 & 618 &, 040 & ,063 & ,951 \\
\hline & $\begin{array}{l}\text { X7: Ruang } \\
\text { administrasi }\end{array}$ &,- 353 & ,640 &,- 298 &,- 551 &, 589 \\
\hline & X8: Ruang guru & - 482 & ,791 & -330 & ,609 &, 551 \\
\hline 1 & $\begin{array}{l}\text { X10: Ruang } \\
\text { pertemuan siswa }\end{array}$ & - 332 & ,734 &,- 284 &,- 452 & .657 \\
\hline & X12: Ruang UKS &,- 325 & 1,089 &,- 270 &,- 298 & ,769 \\
\hline & $\begin{array}{l}\text { X13: Tempat } \\
\text { berolahraga }\end{array}$ & ,292 & 485 & ,233 & 601 &, 556 \\
\hline & X16: Klinik & 019 & 988 & .015 & 020 & 985 \\
\hline & X18: Perpustakaan & 091 & ,456 & .096 & ,200 & 844 \\
\hline & X19: Ruang belajar & 176 & 445 & 148 & ,395 & 697 \\
\hline & X21: Ruang ibadah & ,073 & ,728 & .060 & 101 & 921 \\
\hline & X22: Toilet & ,882 & ,385 & ,778 & 2,294 & ,035 \\
\hline
\end{tabular}




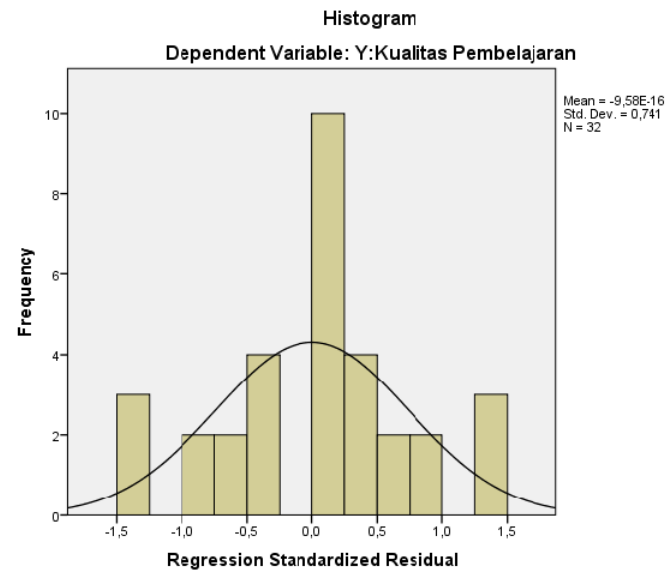

Gambar 1. Histogram Hasil Analisa Data Sarana dan Prasarana Sekolah

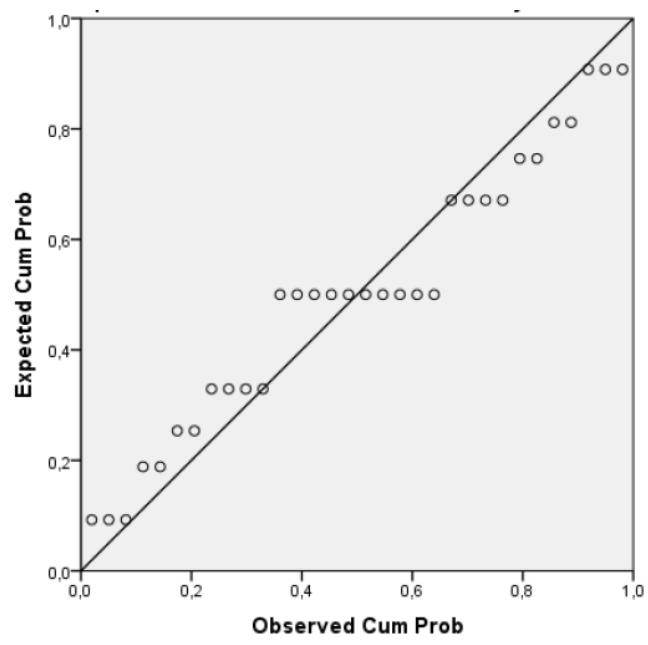

Gambar 2. Grafik Regresi Hasil Analisa Data Sarana dan Prasarana Sekolah

\subsection{Hasil Analisis SPSS 20 Aspek} Penilaian Proses Pembelajaran

\begin{tabular}{|c|c|c|c|c|c|}
\hline \multicolumn{6}{|c|}{$\begin{array}{c}\text { Tabel } 6 . \\
\text { Model Summary }\end{array}$} \\
\hline Model & $\bar{R}$ & R Square & $\begin{array}{l}\text { Adjusted R } \\
\text { Square }\end{array}$ & \begin{tabular}{|c|} 
Std. Error of the \\
Estimate
\end{tabular} & Durbin-Watson \\
\hline 1 &, $587^{\mathrm{a}}$ & 344 &, 032 & ,750 & 2,511 \\
\hline \multicolumn{6}{|c|}{ 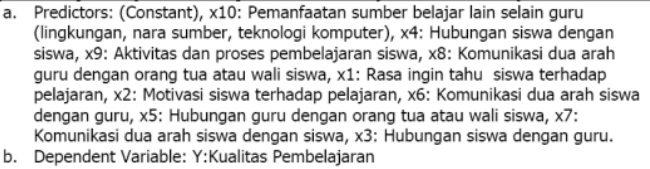 } \\
\hline
\end{tabular}

\begin{tabular}{|c|c|c|c|c|c|c|}
\hline \multicolumn{7}{|c|}{$\begin{array}{l}\text { Tabel } 7 . \\
\text { ANOVA }\end{array}$} \\
\hline \multicolumn{2}{|c|}{ Model } & $\begin{array}{l}\text { Sum of } \\
\text { Squares }\end{array}$ & $\mathrm{df}$ & Mean Square & $F$ & Sig. \\
\hline \multirow{3}{*}{1} & Regression & 6,198 & 10 & ,620 & 1,103 &, $404^{\mathrm{b}}$ \\
\hline & Residual & 11,802 & 21 &, 562 & & \\
\hline & Total & 18,000 & 31 & & & \\
\hline \multicolumn{7}{|c|}{ a. Dependent Variable: Y:Kualitas Pembelajaran } \\
\hline \multicolumn{7}{|c|}{ 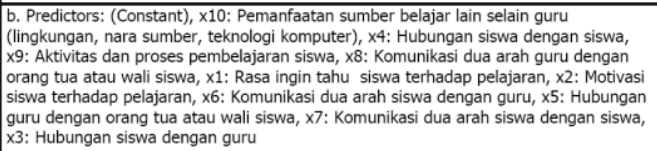 } \\
\hline
\end{tabular}

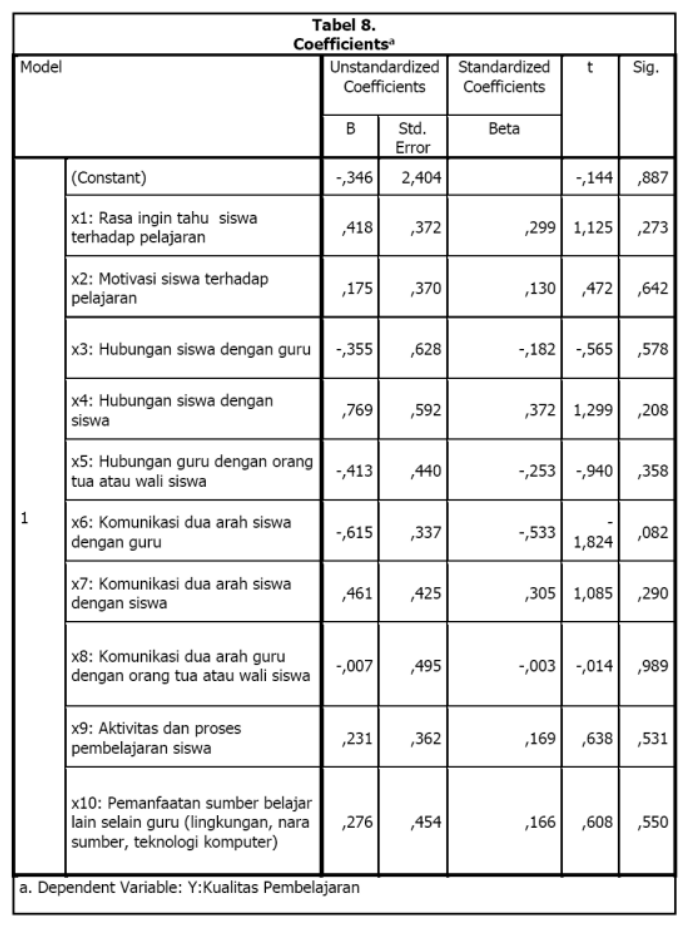

\section{Histogram}

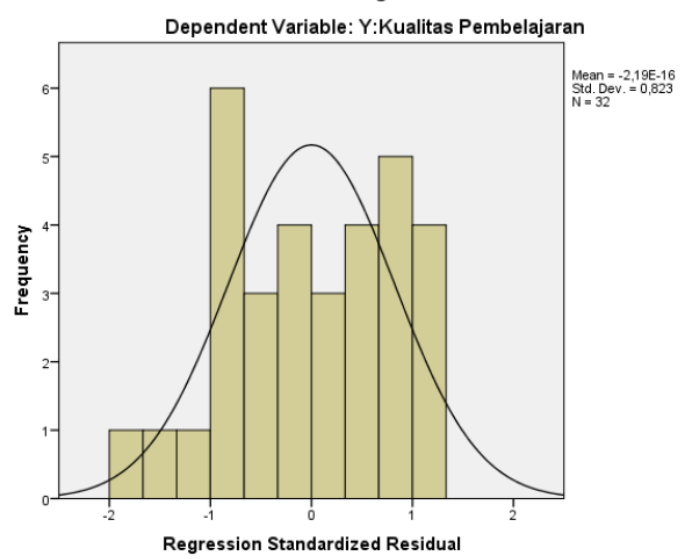

Gambar 3. Histogram Hasil Analisa Data Proses Pembelajaran 
Normal P-P Plot of Regression Standardized Residual

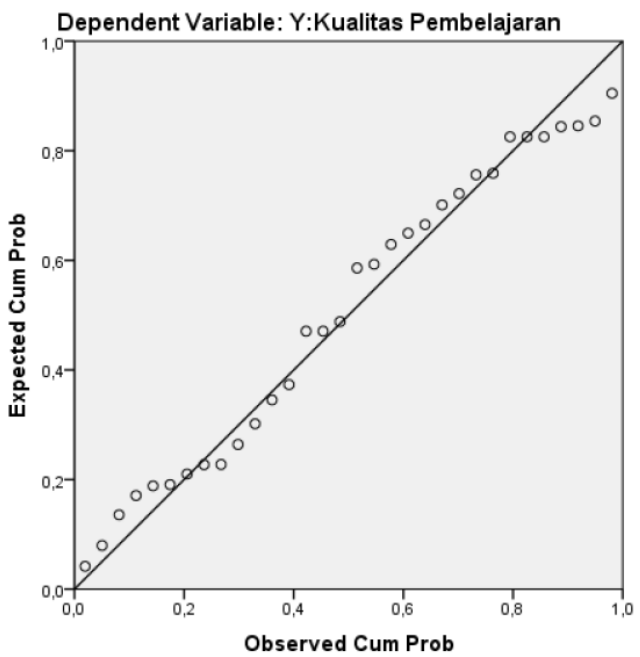

Gambar 4. Grafik Regresi Hasil Analisa Data Proses Pembelajaran.

\section{KESIMPULAN}

A.1. Bentuk matematis analisa regresi berganda hasil analisa data sarana dan prasarana sekolah adalah:

$$
\begin{gathered}
Y=0,317+1,109 * X 1-0,616 * X 2- \\
0,103 * X 5+0,039 * X 6- \\
0,353 * X 7-0,482 * X 8- \\
0,332 * X 10-0,325 * X 12+ \\
0,292 * X 13+0,019 * X 16+ \\
0,091 * X 18+0,176 * X 19+ \\
0,073 * X 21+0,882 * X 22
\end{gathered}
$$

A.2. Nilai Adjusted $R$ Square 0.021 artinya sebesar 2,1\% dipengaruhi oleh:

X22: Toilet, X13: Tempat berolahraga, X18: Perpustakaan, X21: Ruang ibadah, X5: Ruang kepala sekolah, X8: Ruang guru, X19: Ruang belajar, X12: Ruang UKS, X1: Lahan Sekolah, X7: Ruang administrasi, X2: Bangunan Sekolah, X10: Ruang pertemuan siswa, X6: Ruang wakil kepala sekolah, X16: Klinik

A.3. Nilai $R$ square $0<0,463<1$, semakin mendekati satu, maka semakin baik hasil regresi tersebut.

A.4. Uji Anova, terlihat bahwa F tabel SPSS: $1.047<2.52$ ( $\mathrm{F}$ tabel df:reg.14 dan res.17), x10: Pemanfaatan sumber belajar lain selain guru (lingkungan, nara sumber, teknologi komputer), $x 4$ : Hubungan siswa dengan siswa, $x 9$ : Aktivitas dan proses pembelajaran siswa, x8: Komunikasi dua arah guru dengan orang tua atau wali siswa, $x 1$ : Rasa ingin tahu siswa terhadap pelajaran, x2: Motivasi siswa terhadap pelajaran, x6: Komunikasi dua arah siswa dengan guru, x5: Hubungan guru dengan orang tua atau wali siswa, x7: Komunikasi dua arah siswa dengan siswa, x3: Hubungan siswa dengan guru tidak dapat dipakai untuk memprediksi variabel $Y$

A.5. Uji otokorelasi, nilai DW: 2,402 artinya tidak terjadi otokorelasi

A.6. Dari analisis SPSS 20 di atas, secara umum kondisi sarana dan prasarana yang ada sangat perlu untuk ditingkatkan untuk meningkatkan kualitas belajar siswa.

B.1. Bentuk matematis analisa regresi berganda hasil analisa data proses pembelajaran adalah:

$$
\begin{aligned}
& Y=- 0,346+0,418^{*} \times 1+0,175^{*} \times 2- \\
& 0,355^{*} \times 3+0,769^{*} \times 4- \\
& 0,413^{*} \times 5-0,615^{*} \times 6+ \\
& 0,461 * x 7-0,007^{*} \times 8+ \\
& 0,231^{*} \times 9+0,276^{*} \times 10
\end{aligned}
$$

B.2. Nilai Adjusted R Square 0.032 artinya sebesar 3,2 \% dipengaruhi oleh: x10: Pemanfaatan sumber belajar lain selain guru (lingkungan, nara sumber, teknologi komputer), $x 4$ : Hubungan siswa dengan siswa, x9: Aktivitas dan proses pembelajaran siswa, $x 8$ : Komunikasi dua arah guru dengan orang tua atau wali siswa, x1: Rasa ingin tahu siswa terhadap pelajaran, x2: Motivasi siswa terhadap pelajaran, x6: Komunikasi dua arah siswa dengan guru, x5: Hubungan guru dengan orang tua atau wali siswa, x7: Komunikasi dua arah siswa dengan siswa, x3: Hubungan siswa dengan guru

B.3. Nilai $R$ square $0<0.344<1$, semakin mendekati satu, maka semakin baik hasil regresi tersebut.

B.4. Uji Anova, terlihat bahwa F tabel SPSS: $1,103<2.52$ ( $F$ tabel df:reg.10 dan res.21), x10: Pemanfaatan sumber belajar lain selain guru (lingkungan, nara sumber, teknologi komputer), $x 4$ : Hubungan siswa dengan siswa, $x 9$ : Aktivitas dan proses pembelajaran siswa, x8: Komunikasi dua arah guru dengan orang tua atau wali siswa, $\mathrm{x} 1$ : Rasa ingin tahu siswa terhadap pelajaran, x2: Motivasi siswa terhadap 
pelajaran, x6: Komunikasi dua arah siswa dengan guru, x5: Hubungan guru dengan orang tua atau wali siswa, x7: Komunikasi dua arah siswa dengan siswa, x3: Hubungan siswa dengan guru tidak dapat dipakai untuk memprediksi variabel $Y$

B.5. Uji otokorelasi, nilai DW: 2,511 artinya tidak terjadi otokorelasi

B.6. Dari analisis SPSS 20 di atas, secara umum kondisi proses pembelajaran sangat perlu untuk ditingkatkan untuk meningkatkan kualitas belajar siswa.

\section{DAFTAR PUSTAKA}

Indriantoro. Nur, Supomo, Bambang. (2002). Metodologi Penelitian Bisnis untuk Akuntansi \& Manajemen, Yogyakarta: Penerbit BPFE.

Lerbin R.Aritonang. (2005). Kepuasaan Pelanggan Pengukuran dan Penganalisisan dengan SPPS, Jakarta: Penerbit PT. Gramedia Pustaka Utama.

Sugiyono, Statistika untuk Penelitian. (2002). Bandung: Penerbit CV. Alfabeta.

Syahri Alhusin, MS. (2002). Aplikasi Statistik Praktis dengan SPPS 10 for windows, Yogyakarta: Penerbit J \& J Learning.

http://www.google.com, 2014

Wahid Sulaiman, S.Si. (2002), Jalan Pintas Menguasai SPSS 10, Yogyakarta: Penerbit Andi. 